\title{
Kasa Invaze Olmayan Mesane Kanserinde Hex Aminolevulinat Sistoskopisiyle Fotodinamik Tanı: Meta-Analizler Eşliğinde Değerlendirme
}

\section{Hexyl Aminolevulinate-Guided Fluorescence Cystoscopy in the Diagnosis of Patients with Non-Muscle Invasive Bladder Cancer: A Review Based on Meta-Analysis}

\author{
Dr. Emre Tüzel \\ Başkent Üniversitesi Zübeyde Hanım Uygulama ve Araştırma Merkezi, Izmir, Türkiye
}

\section{Özet}

Fotodinamik tanının (FDT) prensibi tümör hücreleri tarafından yüksek oranda emilen foto-duyarlaştırıcı bir ajanın mesane içine instile edilmesini takiben neoplastik hücrelerin mavi-viyole illüminasyon altında kırmızı floresans yayması sonucu görünürlüklerinin arttırılması temeline dayanmaktadır. Fotodinamik tanı ile hem mesane tümörlerinin görülebilmesinin iyileştirilmesi hem de tümör rezeksiyonlarının daha komplet yapılabilmesinin sağlanması amaçlanmaktadır. Bu şekilde rekürrens oranlarının azalacağı ve hastalıksız sağkalımın artacağı öngörülmektedir. Bu derlemede fotodinamik tanısal sistoskopinin kasa invaze olmayan mesane kanseri (KIOMK) tanısındaki yerinin ve tedavi sonuçları üzerine olan etkisinin konuyla ilgili meta-analizler eşliğinde gözden geçirilmesi amaçlanmıştır. Fotodinamik tanısal sistoskopinin KIOMK tanı ve tedavisindeki yerini araştıran dört adet meta-analiz ve bir adet geniş kapsamlı derleme yayınlanmıştır. Çok sayıda prospektif randomize çalışmada FDT sistoskopinin mesane tümörü tespit edebilmede tek başına beyaz ışık eşliğinde yapılan sistoskopiden üstün olduğu gösterilmiştir. Toplamda ise FDT sistoskopi ile Kis tespit etme oranının yaklaşık olarak \%25-\%30 oranında daha fazla olduğu bildirilmektedir. Meta-analizlerin tümünde rezidüel tümör oranlarının FDT sistoskopi uygulanan hastalarda istatistiksel olarak anlamlı derecede düşük olduğu bulunmuştur. FDT sistoskopinin temel limitasyonu \%1 ile \%26 arasında değişen yanlış pozitiflik oranlarıdır. Muhtelif randomize çalışmalarda yan etki yönünden FDT sistokopisi ile beyaz ışık kılavuzluğunda yapılan sistoskopinin yan etkiler açısından farklı olmadığı tespit edilmiştir. KIOMK'inde beyaz ışık eşliğinde yapılan sistoskopiye göre FDT ile öncelikle KiS ve displazi gibi flat lezyonlarda tümör tespitinin daha iyi olduğu ve rezidüel tümör oranının azalıyor olduğu konusunda seviye 1 ve 2 kanıt bulunmaktadır. Bu şekilde hastalığın rekürrens oranlarında anlamlı azalma olduğu çoğu randomize çalışmada teyit edilmiştir. FDT sistoskopi ile hastalığın progresyon oranları azalmamaktadır. (Üroonkoloji Bülteni 2014;13:113-118)

Anahtar Kelimeler: Fotodinamik tanı, kasa invaze olmayan mesane kanseri, hexyl aminolevulinate, 5--Aminolevulinik asit

\begin{abstract}
Summary
The principle of photodynamic diagnosis (PDD) is based on the interaction between a photosensitizing agent with a high uptake by tumor cells and light with an appropriate wavelength which is absorbed by the agent as high energy per photon and re-emitted with a lower energy per photon, thus, visualization is enhanced under under blue light.PDD offers improved visualization of bladder tumors while allowing a more complete transurethral resection. This may facilitate decreased recurrence rates and improved recurrence-free survival. The aim of this review was to evaluate the role of PDD on the diagnosis and treatment of bladder cancer in the light of current meta-analysis. Recently, 4 metaanalysis and a contemporary review have been published on the topic of PDD. Several prospective randomized studies have shown the superiority of PDD-guided cystoscopy over white light cystoscopy alone in tumor detection. PDD cystoscopy increased the detection of carcinoma in situ (CIS) by $25 \%-30 \%$. All meta-analysis have found significantly reduced residual tumor rates with PDD. The main limitation of PDD is the false positive detection rate, which ranges from 1 to $26 \%$. No differences in the rates of adverse events between PDD-guided cystoscopy and white light cystoscopy alone have been found in various randomized studies. Evidence exists in level 1 and 2 that PDD improves tumor detection especially for flat lesions such as CIS or dysplasia and reduces the rate of residual tumor in non-muscle invasive bladder cancer compared with white light cystoscopy alone. A translation of these findings into reduced disease recurrence rates is confirmed my most randomized trials. PDD does not seem to reduce disease progression. (Bulletin of Urooncology 2014;13:113-118)
\end{abstract}

Key Words: Photodynamic diagnosis, non-muscle invasive bladder cancer, hexyl aminolevulinate, 5-Aminolevulinic acid 


\section{Giriş}

Mesane kanseri önemli bir halk sağlığı sorunu olup erkeklerde en sık görülen 4. malignensi kadınlarda ise en sık görülen 11. kanserdir (1). Avrupa kıtasında her yıl tahminen 133,696 yeni olguya mesane kanseri tanısı konulmaktadır (2). Illk tanı anında hastaların yaklaşık \%75-\%80'inde sadece mukoza ve submukozaya sınırlı bulunan kasa invaze olmayan mesane kanseri (KiOMK) tespit edilmektedir. KIOMK'nin öncelikli tedavisinin temelini komplet transüretral rezeksiyon (TUR-mt) oluşturur. Her ne kadar TUR-mt güvenilirliği kanıtlanmış bir yöntem olsa da $\mathrm{pTa} / \mathrm{T} 1$ mesane kanserinin birinci yılda rekürrens ve progresyon olasılıklarının sırasıyla, \%15-\%61 ve < \%1-\%17 arasında değiştiği saptanmıştır (3). Bu olasılıklar 5. yılda rekürrens için \%31-\%78, progresyon için ise < \%1-\%45 olmaktadır. Neticede tümör rezeksiyonu sonrası hastaların önemli kısmına adjuvan intravezikal tedaviler rutin olarak uygulanarak rekürrens oranlarının azaltılması ve olasılıkla da progresyonun inhibe edilmesi veyahut geciktirilmesi amaçlanmaktadır. Kasa invaze hastalığı olanlarda ise radikal tedavilere rağmen 5 yıllık sağkalım oranları \%5'nin altına inmektedir. Bundan dolayı rekürrens ve progresyonu azaltmaya yönelik çabalar KIOMK'nin tedavisinde temel olarak odaklanılan nokta olmaktadır.

Hastalık rekürrensinin tümör hücrelerinin ürotelyuma ekiliminden veya inkomplet rezeksiyon sonucu olabileceği ileri sürülmektedir (4). Illk rezeksiyondan 4-6 hafta sonra yapılan TUR-mt'de T1 mesane kanseri tespit edilen olguların $\% 52$ 'sinde rezidüel hastalık olduğu, bu rezidüel tümörlerin $\% 86^{\prime}$ sının orijinal tümörle aynı lokalizasyonda yerleştiği, \%28'inde ise tümör evresinin yükselerek invaziv hastalık tespit edildiği ve sonuçta radikal sistektomi yapılmak zorunda kalındığı rapor edilmiştir (5). Bu ve benzeri bulgular mesane tümörü rezeksiyonunun komplet olarak doğrulukla yapılmasının ne kadar önemli olduğunu vurgulamaktadır. Rekürrens ve progresyonda rol oynayan diğer bir anahtar nokta ise standart beyaz ışık eşliğinde yapılan sistoskopi ile görülmesi oldukça zor olan karsinoma in-situ (KIS) gibi lezyonlara tanı konulmasındaki zorluktur (6).

Mesane tümörü biyolojisinin daha iyi anlaşılmaya başlanmasına ve intravezikal tedavilerin kullanılmasına rağmen KiOMK'nin terapetik sonuçlarında bir iyileşme olmamıştır (7). Birçok faktörün bu sonuçla ilişkili olduğu düşünülmekte olup bunların, mesane kanseri tanısının atlanması (yanlış negatif incelemeler), rezidüel tümör kalması ile sonuçlanan yetersiz inkomplet TUR yapılması veya KIS gibi standart sistoskopik incelemeyle tanınması zor olan lezyonların gözden kaçması, olabileceği ileri sürülmektedir (8). Bu faktörleri elimine etmeye yarayacak yöntemlerin kullanılması KiOMK'nin tedavi sonuçlarını iyileştireceği düşünülebilir. Geçmişte KiS'i tespit etmeye yönelik olarak normal görünen mesane mukozasından random biyopsiler alınması gündeme gelmiştir. Ancak yapılan araştırmalarda bu uygulamanın avantajının düşük olduğu ayrıca biyopsi alınmasının mesane içinde mukozal bariyerin bozulduğu alanlara tümör implantasyonu riskini arttırabileceğinden rekürrens açısından potansiyel bir tehlike oluşturabileceği bildirilmektedir (9). Bundan dolayı KIS'in tespit edilmesinde daha ileri tetkiklere gereksinim olduğu açıktır.

\section{Fotodinamik Tanısal Sistoskopi}

Geçtiğimiz dekatta klinik uygulamaya giren fotodinamik tanı (FDT) ile hem mesane tümörlerinin görülebilmesinin iyileştirilmesi hem de tümör rezeksiyonlarının daha komplet yapılabilmesinin sağlanması amaçlanmaktadır. Bu şekilde rekürrens oranlarının azalacağı ve hastalıksız sağkalımın artacağı öngörülmüştür.

Fotodinamik tanının prensibi tümör hücreleri tarafından yüksek oranda emilen foto-duyarlaştırıcı bir ajanın mesane içine instile edilmesini takiben neoplastik hücrelerin maviviyole illüminasyon altında kırmızı floresans yayması sonucu görünürlüklerinin arttırılması temeline dayanmaktadır (10). Bu yöntem ile kırmızı florasans yayan porfirinlerin, özellikle de protoporfirin IX (PpIX)'in kanserli hücrelerde birikerek benign ve malign dokular arasındaki görsel kontrast arttırılmaktadır (10). Bu amaçla mesane kanseri tanısında kullanılan 2 ajan mevcuttur: 5-aminolevulinik asit (5-ALA) ve onun derivesi olan hexyl aminolevulinat (HAL). Bunlar pro-ajan olduklarından kendi başlarına bir foto-aktivite göstermemektedirler. Ürotelyal hücrelere transporte olduktan sonra bu pro-ajanlar konvansiyonel hücresel hemobiyosentez metabolizmasında yer alırlar. Sonuçta mesane kanseri hücrelerinde ve prekanseröz dokuda değişen enzim aktiviteleri ile anlamı derecede PpIX birikimi gerçekleşir. Bu esnada mesane duvarı < 380-440 nm dalga boyundaki mavi ışık ile illümine edildiğinde malign dokudaki PpIX, mavi-yeşil görünen benign ürotelyal dokunun aksine, < $635 \mathrm{~nm}$ dalga boyunda kırmızı floresans yayar. Malign ve benign dokuların bu farklı görünümleri tanısal sistoskopi veya TUR-mt esnasında izlenebilmektedir.

Önceki araştırmalarda FDT ile standart beyaz ışık sistoskopisine göre tümör tespitinin iyileştiği gösterilmiştir $(11,12,13,14,15)$. Konvansiyonel beyaz ışık eşliğinde yapılan sistoskopi ile mesane tümörlerinin \%10-\%20'inin gözden kaçtığı tahmin edilmektedir (16). Avrupa Üroloji Derneği (EAU) KiOMK'leri tedavi kılavuzlarında FDT sistoskopinin mesane lezyonlarının tanısında, özellikle de KIS'in tespitinde önemli bir rol oynadığı vurgulanmaktadır (17). Ancak son dönemde yayınlanan bazı randomize prospektif çalışmaların sonuları FDT sistoskopinin avantajlarının sorgulanmasına yol açmıştır $(18,19)$. Bu bahsi geçen yayınlarda KIOMK'de FDT ile daha yüksek oranda tümör tespit edilmesinin rekürrenssiz sağkalımı veya progresyonsuz sağkalımı etkilemiyor olduğu bildirilmiştir $(18,19)$.

$\mathrm{Bu}$ derlemede fotodinamik tanısal sistoskopinin KIOMK tanısındaki yerinin ve tedavi sonuçları üzerine olan etkisinin konuyla ilgili meta-analizler eşliğinde gözden geçirilmesi amaçlanmıştır.

\section{İncelenen Meta-analizlerin Tanımlanması}

Fotodinamik tanısal sistoskopinin KIOMK tanı ve tedavisindeki yerini araştıran dört adet meta-analiz ve bir adet geniş kapsamlı derleme yayınlanmıştır $(2,8,20,21,22)$. Bu meta-analizlerin metodolojik farklılıkları mevcut olduğundan bunların sonuçları da bu farklılıklar göz önüne alınarak değerlendirilmelidir.

Kausch ve ark.'nın 2010 yılında yayınladıkları meta-analizde 1990 ile 2008 yılları arasında İngilizce, Almanca ve Fransızca dillerinde yayınlanmış olan, beyaz ışık kılavuzluğunda sistoskopi veya TUR-mt yapılan hastaların, beyaz ışık sonrası FDT sistoskopi veya fotodinamik TUR-mt yapılanlarla karşılaştıran 14 randomize prospektif çalışmadan üretilmiş 21 makale dahil edilmiştir (8). Mowatt ve ark.'nın 2011 yılında basılan meta-analizine 1966 ile 2008 yılları arasında İngilizce olarak yayınlanmış 27 randomize prospektif kontrollü çalışmadan yayınlanan 36 makale dahil edilmiştir (20). Shen ve ark.'nın 2012'de yayınlanan 
meta-analizine 2011 yılına kadar yapılan FDT sistoskopinin tanısal doğruluğunu ve terapetik sonuçlara etkisini araştıran Ingilizce olarak yayınlanmış 14 çalışma dahil edilmeye uygun görülmüştür (21). Burger ve ark.'nın 2013 yılında yayınlanan meta-analizine Temmuz 2011 tarihine kadar herhangi bir dilde yayınlanmış olan ve sadece HAL kullanılarak yapılmış olan 11 makale dahil edilmiştir (22). Ayrıca devam etmekte olan prospektif çalışmalarda yer alan hastaların ham sonuçlarının araştırmacılarla kişisel kontakt kurularak temin edilen bilgiler de meta-analize eklenmiştir. Bu meta-analizde 6 çalışmaya ait hasta bilgilerinin sponsor firma (Photocure) tarafından oluşturulmuş bir database'den temin edildiği araştırmacılar tarafından deklare edilmiştir (22). Rink ve ark.'nın kapsamlı derlemesinde ise 1974 ile Ekim 2012 tarihleri arasında İngilizce olarak yayınlanmış 44 orijinal makale ve 3 meta-analiz dahil edilmiştir (2).

5-ALA fotodinamik tanı için geliştirlen ilk ajandır. Bundan dolayı literatürde 5-ALA kullanılarak yapılmış araştırma sayısı çok daha fazladır. Diğer taraftan FDT için ABD'de onay almış olan tek ajan HAL'dır. HAL'ın lokal biyo-uyumluluk, daha iyi stabilize olma, floresans yoğunluğunu arttırabilme ve daha homojen PpIX tutulumu ve dağılımı sağlama gibi özelliklerinin 5-ALA'den daha iyi olduğu bildirilmektedir (23). Bu iki ajanın duyarlılık ve özgüllüklerinin hastalığın tanısında benzer olduğu yayınlanmıştır (20).

Yukarıda tanımlanmış olan meta-analizlerde FDT sistoskopinin beyaz ışık eşliğinde yapılan sistoskopiye göre Ta/T1 tümör ve Kis tanısında ilave bir katkı sağlayıp sağlamadığı, kontrol sistoskopileriyle değerlendirilen rezidüel tümör sıklığı, rekürrens üzerine bir etkisinin olup olmadığı, rekürrenssiz ve progresyonsuz sağkalım üzerine etkisi gibi noktalar değerlendirilmiştir.

\section{Fotodinamik Tanısal Sistoskopinin Mesane Kanseri Tanısındaki Yeri}

Çok sayıda prospektif randomize çalışmada FDT sistoskopinin mesane tümörü tespit edebilmede tek başına beyaz ışık eşliğinde yapılan sistoskopiden üstün olduğu gösterilmiştir (2). Kausch'un meta-analizinde FDT sistoskopi ile olguların \%5-\%49'unda beyaz ışık eşliğinde yapılan sistoskopiye kıyasla ilave mesane tümörü tanısı konulabildiği, KIS için ise ilave tanı oranlarının \%17-\%78 arasında değiştiği bulunmuştur (8). Bu bulgular Mowatt ve ark.'nın meta-analizinde desteklenmiştir. Bu çalışmada FDT sistoskopinin tümör tespit etmedeki tanısal duyarlılığının \%92, beyaz ışık sistoskopisinin ise \%71 olduğu bildirilmiştir (20). Sadece HAL kullanılarak yapılan çalışmaların incelendiği diğer bir meta-analizde beyaz ışık eşliğinde yapılan sistoskipye kıyasla ilave tümör tespit oranları Ta/T1 tümörler ve KiS için sırasıyla \%14,7, \%10,8 ve \%40,8 olarak bildirilmiştir (22). Bu bulguların aksine Shen ve ark.'nın meta-analizinde beyaz ışık ve FDT sistoskopi arasında tümör tespit oranları, beyaz ışık için \%90,9, FDT için \%91,8, yani benzer bulunmuştur (21). Ancak bu meta-analiz aynı serilere ait multipl makaleyi incelemeye dahil etmiş olduğu için ve benzer makaleleri inceleyen meta-analizlerin bulgularıyla tezat sonuçlar bildirdiği için eleştirilmektedir (2). Ancak son dönemde yayınlanmış olan ve 5-ALA kullanılarak yapılan 2 prospektif randomize çalışmada FDT sistoskopinin ilave tümör tespitinde beyaz ışık sistoskopisine göre daha iyi olmadığı rapor edilmiştir $(18,19)$.

Çok sayıda prospektif çalışmada özellikle multipl papiller tümörlü hastalarda fotodinamik tanının faydalı olduğu bildirilmiştir $(12,24)$. Yöntemin Kís'in tespitindeki yararı ise daha belirgindir.
KiS tespit etme oranları FDT sistoskopi ile \%49-\%100 arasında, beyaz ışık eşliğinde yapılan sistoskopi ile \%5-\%68 arasında değişmektedir (2). Eğer sadece beyaz ışık sistoskopisi yapılsaydı olguların \%16 ile \%76'sında Kís'in tanısının atlanacağı bildirilmiştir (2). Toplamda ise FDT sistoskopi ile KiS tespit etme oranının yaklaşık olarak \%25-\%30 oranında daha fazla olduğu rapor edilmektedir $(14,25,26)$. Nihayetinde FDT sistoskopi Kis tespit edilmesini anlamlı derecede arttırmaktadır.

İdrar sitolojisinin özellikle yüksek dereceli tümörlerde yüksek duyarlılığa sahip olduğu ve üst üriner sistem veya mesanede bir tümöral oluşumun varlığına işaret edebileceği bilinmektedir (17). Burada problem olan ise, idrar sitolojisi pozitif olan bir hastada konvansiyonel beyaz ışık sistoskopisinin normal bulunmasıdır. Çünkü epitelde kalınlaşmaya neden olmayan KIS, displazi gibi veya küçük papiller tümöral oluşumlar gibi düz ürotelyal lezyonlar beyaz ışık eşliğinde yapılan sistoskopi ile gözden kaçabilmektedir. Bir prospektif (27) ve bir retrospektif (28) çalışmada, idrar sitolojisi pozitif ancak sistoskopisi normal bulunmuş olan hastalarda FDT sistoskopinin etkinliği araştırılmıştır. Her iki çalışmada da fotodinamik tanısal sistoskopinin ilave malign ve premalign lezyonları tespit edebildiği bildirilmiştir. Ancak günümüz tedavi kılavuzlarında sistolojisi pozitif sistoskopisi normal olan hastalardan random mesane biyopsisi alınması önerilmektedir. Yukarıda fotodinamik yöntemin bu grup hastalardaki olası yararlarına atıfta bulunulan çalışmaların hiçbirinde random biyopsi alınmamış olduğundan, bunların sonuçları dikkatle karşılanmalıdır.

Fleksibl fotodinamik tanısal sistoskopinin etkinliğini araştıran çalışmalarda flexibl FDT'nin beyaz ışık sistoskopisinden daha iyi performans gösterdiği ancak rijid FDT sistoskopiden daha iyi olmadığı bildirilmektedir (29). Bundan dolayı teknikte daha ileri gelişmeler kaydedilinceye kadar rijid FDT sistoskopi tercih edilecek seçenek olarak kalmaya devam edecektir.

\section{Fotodinamik Tanısal Sistoskopinin Rezidüel Tümör Üzerine Etkisi}

Rezidüel tümör sıklığını araştıran çalışmalarda, ilk rezeksiyonları beyaz ışık sistoskopisi + FDT sistoskopi eşliğinde TUR-mt yapılan hastalar ile ilk rezeksiyonları tek başına beyaz ışık sistoskopisi eşliğinde yapılanlar karşılaştırılmıştır. Çalışmaların çoğunda ikinci rezeksiyonlar beyaz ışık sistoskopisi eşliğinde gerçekleştirilmiştir. Re-rezeksiyon aralıkları 10 gün ile 6 hafta arasında değişen çok sayıda randomize çalışmada gösterilmiş olduğu üzere FDT sistoskopi kılavuzluğunda yapılan TUR-mt ile daha komplet bir rezeksiyon yapılabilmektedir (2). Metaanalizlerin tümünde rezidüel tümör oranlarının fotodinamik tanısal sistoskopi uygulanan hastalarda istatistiksel olarak anlamlı derecede düşük olduğu bulunmuştur $(8,20,21)$. Burger ve ark.'nın meta-analizinde rezidüel tümör oranıyla ilgili bir bilgi sunulmamıştır. Kausch'un meta-analizinde tüm hastaların bilgileri için bir havuz oluşturularak, FDT sistoskopi yapılanlarda rezidüel tümör sıklığının \%15, beyaz ışık sistoskopisi yapılanlarda \%35 olduğu rapor edilmiştir (8). Burada random etki oranı 0,28 olarak bulunmuştur. Bir başka deyişle eğer beyaz ışık sistoskopisi ile 3 hastanın 1'inde rezidüel tümör saptanırsa, bu oran FDT sonrası 8 hastanın 1'ine denk gelmektedir (8). Sonuç olarak fotodinamik tanısal sistoskopinin rezidüel tümör oranlarını anlamlı derecede azalttığı konusunda kuvvetli (seviye 1) kanıt bulunmaktadır. 
Fotodinamik Tanısal Sistoskopinin Rekürrens Üzerine Etkisi Bir meta-analizde FDT sistoskopi yapılanlarda anlamlı ölçüde daha az rekürrens olduğu, FDT grubunda beyaz ışık grubuna göre 12. ve 24. aylarda rekürrenssiz sağkalımın sırasıyla \%15,8$\% 27$ ve $\% 12-\% 15$ daha yüksek olduğu bulunmuştur. Mowatt'ın meta-analizinde de 24 aylık izlemde rekürrenssiz sağkalımın istatistiksel olarak anlamlı derecede FDT sistoskopi yapılanlarda daha uzun olduğu bulunmuştur (RR: 1,18-1,59, \%95 güvenlik aralığında). Ancak 12. ayda bir fark gözlenmemiştir. Shen'in meta-analizinde ise 3., 12. ve 24. aylarda FDT ve beyaz ışık gruplarında rekürrenssiz sağkalım arasında fark bulunmamıştır (12 ay için RR: 0,99, \%95 güvenlik aralığında; 0,94-1,04, $p=0,57$ ve 24 ay için RR: $1,02, \% 95$ güvenlik aralığında, 0,98 $1,06, p=0,35)$. Fakat bu meta-analizin rekürrenssiz sağkalım ile ilgili sonuçlarının (21), bu konuyla ilgili uzun dönem takip ortaya koyan 3 ayrı çalışmanın bulgularıyla zıtlık gösteriyor olmasından dolayı, dikkatli bir şekilde yorumlanması gerektiği ileri sürülmektedir (2).

Sadece HAL'la yapılan çalışmaların dahil edildiği Burger'in metaanalizinde rekürrens oranları HAL sistoskopisi grubunda anlamlı derecede düşük bulunmuştur. Toplam rekürrens oranları HAL grubunda \%34,5, beyaz ışık grubunda \%45,4 (RR: 0,76, $0,62-0,92, p=0,006)$ olarak bildirilmiştir. Ancak araştırmacılar subgrup analizlerinde aradaki farkların ve risk oranlarının istatistiksel anlamlılı̆ın sınııında yer aldığını rapor etmişlerdir. Kapsamlı bir derlemede ise rekürrenssiz sağkalımı rapor eden 13 prospektif randomize çalışmanın sonuçları irdelenmiştir (2). Buna göre rekürrenssiz sağkalım oranlarının 12. ve 24 . aylarda FDT grubunda beyaz ışık grubuna göre sırasıyla \%10,9$\% 27$ ve \%13-\%24 oranında daha yüksek olduğu bildirilmiştir. Bunların aksine son dönemde yayınlanmış 3 çalışmada FDT grubu ve beyaz ışık grubu arasında rekürrens yönünden bir fark olmadığı bildirilmiştir $(18,19,30)$. Bu bulguların önceki metaanalizlerin bulgularılla benzerlik göstermemesinin nedenlerinin hasta heterojenitesi, düşük dereceli tümörlü hasta sayııının fazla olması, KiS oranının azlığı, adjuvan intravezikal tedavi kullanım oranlarındaki farklııklar ve randomize bir çalışma dahilinde standart beyaz ışı sistoskopilerinin daha dikkatli yapılıyor olması gibi faktörlerle ilişkili olabileceği ileri sürülmektedir.

Adjuvan intravezikal tedavi uygulamaları orta-yüksek risk grubundaki KIOMK'li hastalara önerilmekte olup, bu yaklaşım rekürrens ve progresyonda azalmaya neden olabilmektedir. Fakat FDT sistoskopinin mesane kanseri rekürrensinin gerçekteki doğal seyri üzerine olan etkisini kestirmek şu durumda çok zordur, çünkü bu atfedilen çalışmaların hiçbirinde çalışma bulguları intravezikal tedavilerin etkilerine göre yeterince uyarlanmamıştır (2). Intravezikal tedavi TUR-mt sonuçlarını özellikle de rekürrenssiz sağkalım ve progresyonsuz sağkalım oranlarını etkileyebilir. Ancak fotodinamik tanıyla ilgili çalışmaların büyük bir çoğunluğunda bu olası etki araştırılmamıştır.

Rekürrense kadar geçen medyan zaman aralığının da fotodinamik tanısal sistoskopi yapılan hastalarda beyaz ışık sistoskopisi yapılanlara göre 7-9 ay kadar anlamlı ölçüde uzun olduğu bildirilmektedir $(31,32,33)$. Bunun haricinde FDT yönteminin hastalık progresyonu üzerine olan etkisi tam olarak bilinmemektedir.

\section{Fotodinamik Tanısal Sistoskopi Tekniğinin Dezavantajları}

FDT sistoskopinin temel limitasyonu \%1 ile \%26 arasında değişen yanlış pozitiflik oranlarıdır (2). Zaman içinde fotodinamik tanıyla ilgili deneyim arttıkça ve teknoloji ilerledikçe bu yanlış pozitif tümör tespit etme oranlarının azalacağı ileri sürülmektedir. Aktif üriner sistem enfeksiyonu, son 6 hafta içinde BCG instilasyonu veya TUR-mt yapılması gibi non-spesifik enflamasyon etkeni olabilecek faktörlerin varlığında FDT ile yanlış pozitif sonuçlar elde edilebilmektedir (4). Bu faktörler mukozal enflamasyon ve olasilıkla skar dokusu oluşumuna sebebiyet vererek mesane duvarının mavi ışık altında incelenmesinde kırmızı illüminasyon yaymasına neden olabilirler. Bu etkiyi ortadan kaldırmak için araştırıcılar FDT'nin TUR-mt veya BCG instilasyonundan 3-4 ay sonra uygulanmasını önermektedirler. Ancak son 4 ay içinde tek doz BCG verilmiş olanlarda veya mitomisin-C alanlarda bu kadar beklemeye gerek olmadığı söylenmektedir (34). Vurgulanması gereken bir nokta ise beyaz ışık eşliğinde yapılan sistoskopilerdeki yanlış pozitiflik oranlarıyla ilgili çok az bilgiye sahip olunduğudur. Çalışmaların büyük çoğunluğunda random biyopsi yapılmamış olduğundan FDT ile ilgili yanlış negatif sonuçlar ihtiyatla değerlendirilmelidir. Bundan dolayı 'yanlıs negatif' bulgular çoğunlukla FDT ile gözden kaçanlardan ziyade beyaz ışık sistoskopileriyle tespit edilenler olmaktadır. Ek olarak bu oranı rapor etmede kullanılabilecek uygun bir metod bulunmamaktadır. Buna rağmen FDT sistoskopi ile gözden kaçırılan lezyon oranının \%1 ile \%11 arasında değişmekte olduğu bildirilmektedir (2).

Tekniğin kendisiyle ilgili bazı durumlarda FDT sistoskopi sonuçlarını etkileyebilmektedir. Örneğin HAL tipik olarak girişimden $60 \mathrm{dk}$ önce mesaneye instile edilmektedir. Şiddetli urgency yakınması olan hastalar ilacı mesanelerinde yeterince tutamadıklarından dolayı ilacın mukozal emilimi azalabilir. Bu da floresans sonuçlarını etkileyebilir. Yöntemle ilgili spesifik teknik ekipman gereksinimi olduğundan, ışık kabloları, kameralar ve teleskoplar standart olanlarla karıştıılabilinerek yanlış bulgular elde edilmesine neden olabilirler. Ayrıca mavi ışık floresans ile uyumlu sistoskopik ekipmanın doğru bir şekilde muhafaza edilmesi FDT yöntemin kalitesinin sürdürülebilmesi için temeldir (35).

Mavi ışık floresans altında TUR-mt yapmak daha zor olduğundan, çoğu cerrah FDT'yi sadece rezidüel tümör dokusunun veya ilave lezyonların varlığının tespit edilmesinde kullanmaktadır. Genel olarak FDT'nin dezavantajlarının minör olduğu, yanlış pozitiflik oranlarının artan tecrübe ile zaman içinde azaldığı ileri sürülmektedir. Beyaz ışık eşliğinde sistoskopi ve sonrasında FDT sistoskopi yapılarak komplet mesane haritası çıkarılmasının hatalı sonuçları azaltabileceği düşünülmektedir.

\section{Yan Etkiler}

5-ALA ve HAL hastalar tarafından iyi tolere edilen güvenilir ilaçlardır. FDT'nin yan etkilerini araştıran çalışmalarda bu oranın $\% 22,5$ ile $\% 80,5$ arasında değişmekte olduğu ve sadece olguların \%0-\%2,4'ünde bu yan etkilerin direkt olarak fotodinamik ajanlarla ilişkili olduğu rapor edilmiştir (2). Genel olarak çoğu olay standart sistoskopi ve TUR-mt ile ilişkili yan etkiler şeklinde gerçekleşmektedir. Muhtelif randomize çalışmalarda yan etki yönünden FDT sistokopisi ile beyaz ışık kılavuzluğunda yapılan sistoskopinin yan etkiler açısından farkı olmadığı tespit edilmiştir (2). Ilacın intravezikal instilasyonuna bağlı potansiyel yan etkilerin, bu semptomların hiçbirinin direkt olarak ilaç instilasyonuyla ilişkili olduğu kanıtlanmamış olmakla birlikte, penil enfeksiyon ve ağrı, gros hematüri, mesane ağrısı ve spazmı, pollaküri olduğu bildirilmektedir. 


\section{Maliyet}

Mesane kanserinin yüksek rekürrens oranları veya progresyon riski ilk tanı sonrasında hastaların uzun süre sistoskopi ile takip edilmelerini gerektirmektedir. Bu takiplerin intravezikal uygulamalar gibi muhtelif tedavi yöntemleriyle, sitolojik veya moleküler üriner testler ile kombine edilmesi ve KiOMK'ye bağlı mortalitenin düşük olması gibi faktörler mesane kanserlerini tedavisi en pahalı malignensilerden biri haline getirmektedir (36). Mesane kanseri tedavisinin maliyetiyle ilgili karşılaştırmalar yapmak komplike ve zor bir konudur çünkü ülkeler genelinde bu konu çok değişkenlik göstermektedir. Buna rağmen genel olarak FDT sistoskopinin standart beyaz ışık eşliğinde yapılan sistoskopiye kıyasla ilave bir maliyet artışına neden olduğu açıktır. Burada kullanılan fotodinamik ajan, işlem öncesi üretral katater takılması ve sistoskopi için spesifik ekipman temin etme gereksinimi bu ilave maliyet artışından sorumlu olmaktadır. FDT'nin maliyet-etkinlik değerlendirilmesinin incelendiği bir çalışmada, yazarlar FDT ile tümör tanısının daha doğrulukla konabilmesi ve daha komplet bir TUR yapılabilmesi sonucunda rekürrens oranlarının ve tekrarlayan TUR-mt'lerin azalacağı ve sonuçta uzamış rekürrenssiz sağkalımın kontrol sistoskopisi sayısında azalmaya yol açarak toplam maliyeti düşürebileceği ileri sürülmüştür (37). Bir çalışmada rekürrens oranında azalmaya bağlı olarak FDT ile tekrarlayan TUR-mt oranlarında \%25 oranında azalma olduğu ve bu şekilde FDT sistoskopinin maliyet açısından etkin olduğu bildirilmiştir (36).

Ancak FDT sistokopi ile rekürrens oranlarında azalma olmadığını rapor eden çalışmaların yayınlanması, güncel pratikte bu bahsedilen maliyet analizlerinin gerçeği yansıtmayabileceğini gündeme getirmiştir $(18,19)$. Sonuçta yeni teknolojilerin makul bir ek maliyet yükü getirebileceği, ancak ekonomik modellerin kompleks olması ve FDT'nin maliyet hesabının multifaktoriyel olması, bu konuyla ilgili güncel maliyet-etkinlik analizi modellerinin tüm değişkenleri hesaba katmada yetersiz kalmasıyla sonuçlanmaktadır.

\section{Sonuç}

Kasa invaze olmayan mesane kanserinde beyaz ışık eşliğinde yapılan sistoskopiye göre FDT ile öncelikle KIS ve displazi gibi flat lezyonlarda tümör tespitinin daha iyi olduğu ve rezidüel tümör oranının azalıyor olduğu konusunda seviye 1 ve 2 kanıt bulunmaktadır. Bu şekilde hastalığın rekürrens oranlarında anlamlı azalma olduğu hepsinde olmamakla birlikte çoğu randomize çalışmada teyit edilmiştir. FDT sistoskopi ile hastalığın progresyon oranları azalmamaktadır. FDT sistoskopinin kullanılmasının düşünüldüğü durumlarda önceki tedavilere bağlı yanlış pozitiflikleri önlemek için, yöntem ya ilk rezeksiyonda veya önceki rezeksiyondan makul bir süre sonra uygulanmalıdır. FDT sistoskopinin izlem için ve poliklinik koşullarında kullanılması önerilmemektedir.

Mesane tümörlerinin ve tümörlere ait marjinlerin FDT ile daha kati bir şekilde görüntülenebiliyor olması, bu heterojen hastalığın tedavisinde hayati önemi olan TUR-mt'yi cerrahların daha iyi yapabilmesine olanak tanıyacağı düşünülmektedir. Gelecekte yapılacak, uzun süreli takip ile iyi planlanmış prospektif randomize çalışmalar sonucunda FDT sistoskopinin hem hastalık üzerine olan gerçek etkisi hem de maliyet etkinlik analizi konusu daha iyi anlaşılacaktır.

\section{Kaynaklar}

1. Grasso M. Bladder Cancer: a major public health issue. Eur Urol Suppl 2008;7:510-515.

2. Rink M, Babjuk M, Catto JWF, et al. Hexyl aminolevulinate-guided fluorescence cystoscopy in the diagnosis and follow-up of patients with non-muscle-invasive bladder cancer: a critical review of the current literature. Eur Urol 2013;64:624-638.

3. Sylvester RJ, van der Meijden AP, Oosterlinck W, et al. Predicting recurrence and progression in individual patients with stage $\mathrm{Ta} T 1$ bladder cancer using EORTC risk tables: a combined analysis of 2596 patients from seven EORTC trials. Eur Urol 2006;49:466-477.

4. Bunce $C$, Ayres BE, Griffiths $L$, et al. The role of hexylaminolevulinate in the diagnosis and follow-up of non-muscle invasive bladder cancer. BJU Int 2010;105(suppl 2):2-7.

5. Schwaibold HE, Sivalingam S, May $F$, et al. The value of a second transurethral resection for $\mathrm{T} 1$ bladder cancer. BJU Int 2006;97:1199-1201.

6. Witjes JA. Bladder carcinoma in situ in 2003: state of the art. Eur Urol 2004;45:142-146.

7. Rink M, Cha EK, Green D, et al. Biomolecular predictors of urothelial cancer behavior and treatment outcomes. Curr Urol Rep 2012;13:122-135.

8. Kausch I, Sommerauer M, Montorsi F, et al. Photodynamic diagnosis in non-muscle invasive bladder cancer: a systemic review and cumulative analysis of prospective studies. Eur Urol 2010;57:595-606.

9. van der Meijden A, Oosterlinck W, Brausi M, et al. Significance of bladder biopsies in Ta,T1 bladder tumors: a report from the EORTC Genito-Urinary Tract Cancer Cooperative Group. EORTC-GU Group Superficial Bladder Committee. Eur Urol 1999;35:267-271.

10. Zaak D, Karl A, Knuchel R, et al. Diagnosis of urothelial carcinoma of the bladder using fluorescence endoscopy. BJU Int 2005;96:217-222.

11. Schmidbauer J, Witjes F, Schmeller N, et al. Improved detection of urothelial carcinoma in situ with hexaminolevulinate fluorescence cystoscopy. J Urol 2004;171:135-138.

12. Grossman HB, Gomella L, Fradet $Y$, et al. A phase III, multicenter comparison of hexaminolevulinate fluorescence cystoscopy and white light cystoscopy for the detection of superficial papillary lesions in patients with bladder cancer. J Urol 2007; 178:62-67.

13. Fradet $Y$, Grossman HB, Gomella $L$, et al. A comparison of hexaminolevulinate fluorescence cystoscopy and white light cystoscopy for the detection of carcinoma in situ in patients with bladder cancer: a phase III, multicenter study. J Urol 2007;178:68-73.

14. Jocham D, Witjes F, Wagner S, et al. Improved detection and treatment of bladder cancer using hexaminolevulinate imaging: a prospective, phase III multicenter study. J Urol 2005;174:862-866.

15. Jihlinski P, Guillou L, Karlsen SJ, et al. Hexyl aminolevulinate fluorescence cystoscopy: new diagnostic tool for photodiagnosis of superficial bladder cancer--a multicenter study. J Urol 2003;170:226-229.

16. Jichlinski P, Leisinger HJ. Fluorescence cystoscopy in the management of bladder cancer: a help for the urologist! Urol Int 2005;74:97-101.

17. Babjuk $M$, Burger $M$, Zigeuner $R$, et al. EAU guidelines on nonmuscle-invasive urothelial carcinoma of the bladder: update 2013. Eur Urol 2013;64:639-653.

18. Schumacher MC, Holmang S, Davidsson $T$ et al. Transurethral resection of non-muscle invasive bladder transitional cell cancers with or without 5-aminolevulinic acid under visible and fluorescent light: results of a prospective randomized multicenter study. Eur Urol 2010;57:293-299.

19. Stenzl A, Penkoff H, Dajc-Sommerer E, et al. Detection and clinical outcome of urinary bladder cancer with 5-aminolevulinic acidinduced fluorescence cystoscopy: A multicenter randomized, doubleblind, placebo-controlled trial. Cancer 2011;117:938-947. 
20. Mowatt G, N'Dow J, Vale L, et al. Photodynamic diagnosis of bladder cancer compared with white light cystoscopy: Systematic review and meta-analysis. Int J Technol Assess Health Care 2011;27:3-10.

21. Shen P, Yang J, Wei W, et al. Effects of fluorescent light-guided transurethral resection on non-muscle-invasive bladder cancer: a systematic review and meta-analysis. BJU Int 2012;110:209-215.

22. Burger $M$, Grossman HB, Droller $M$, et al. Photodynamic diagnosis of non-muscle-invasive bladder cancer with hexaminolevulinate cystoscopy: a meta-analysis of detection and recurrence based on raw data. Eur Urol 2013;64:846-854.

23. Marti A, Jichlinski $P$, Lange $N$, et al. Comparison of aminolevulinic acid and hexylester aminolevulinate induced protoporphyrin IX distribution in human bladder cancer. J Urol 2003;170:428-432.

24. 24.Geavlete B, Multescu R, Georgescu D, et al. Treatment changes and long-term recurrence rates after hexaminolevulinate (HAL) fluorescence cystoscopy: does it really make a difference in patients with non-muscle-invasive bladder cancer (NMIBC)? BJU Int 2012;109:549-556.

25. Kriegmair $\mathrm{M}$, Zaak $\mathrm{D}$, Rothenberger $\mathrm{KH}$, et al. Transurethral resection for bladder cancer using 5-aminolevulinic acid induced fluorescence endoscopy versus white light endoscopy. J Urol 2002; 168:475-478.

26. Stenzl A, Burger $M$, Fradet $Y$, et al. Hexaminolevulinate guided fluorescence cystoscopy reduces recurrence in patients with nonmuscle invasive bladder cancer. J Urol 2010;184:1907-1913.

27. Ray ER, Chatterton K, Khan MS, et al. Hexylaminolaevulinate 'blue light' fluorescence cystoscopy in the investigation of clinically unconfirmed positive urine cytology. BJU Int 2009;103:1363-1367.

28. Karl A, Tritschler S, Stanislaus $P$, et al. Positive urine cytology but negative white light cystoscopy: an indication of fluorescence cystoscopy? BJU Int 2009;103:484-487.
29. Loidl W, Schmidbauer J, Susani M, et al. Flexible cystoscopy assisted by hexaminolevulinate induced fluorescence: a new approach for bladder cancer detection and surveillance? Eur Urol 2005; 47:323-326.

30. Grossman HB, Stenzl A, Fradet Y, et al. Long-term decrease in bladder cancer recurrence with hexaminolevulinate enabled fluorescence cystoscopy. J Urol 2012;188:58-62.

31. Daniltchenko DI, Riedl CR, Sachs MD, et al. Long-term benefit of 5-aminolevulinic acid fluorescence assisted transurethral resection of superficial bladder cancer: 5 -year results of a prospective randomized study. J Urol 2005;174:2129-2133.

32. Riedl CR, Daniltchenko DI, Koenig F, et al. Fluorescence endoscopy with 5-aminolevulinic acid reduces early recurrence rate in superficial bladder cancer. J Urol 2001;165:1121-1123.

33. Babjuk M, Soukup V, Petrik R, et al. 5-aminolaevulinic acid-induced fluorescence cystoscopy during transurethral resection reduces the risk of recurrence in stage $\mathrm{Ta} / \mathrm{T} 1$ bladder cancer. BJU Int 2005;96:798-802.

34. Witjes JA, Redorta JP, Jacqmin D, et al. Hexaminolevulinate-guided fluorescence cystoscopy in the diagnosis and follow-up of patients with non-muscle-invasive bladder cancer: review of the evidence and recommendations. Eur Urol 2010;57:607-614.

35. Mark JR, Gelpi-Hammerschmidt F, Trabulsi EJ, et al. Blue light cystoscopy for detection and treatment of non-muscle invasive bladder cancer. Can J Urol 2012;19:6227-6231.

36. Sievert KD, Amend $B$, Nagele $U$, et al. Economic aspects of bladder cancer: what are the benefits and costs? World J Urol 2009;27:295-300.

37. Stenzl A, Hötl L, Bartsch G. Fluorescence assisted transurethral resection of bladder tumors: is it cost effective? Eur Urol 2001;39:31. 